\title{
Effect of the GH secretagogue L-163,255 and restricted feeding time on GH pulsatility in the rat
}

\author{
Anargyros N Moulas, Richard J Krieg Jr ${ }^{1,2}$, Johannes D Veldhuis ${ }^{4}$ and James C M Chan ${ }^{1,3}$ \\ Department of Animal Production, Technological Education Institute (T.E.I.) of Larissa, GR 41110 Larissa, Greece, Departments of ${ }^{1}$ Pediatrics, \\ ${ }^{2}$ Anatomy and ${ }^{3}$ Biochemistry and Molecular Biophysics, Virginia Commonwealth University's Medical College of Virginia Campus, Richmond, \\ Virginia 23298-0498, USA and ${ }^{4}$ Division of Endocrinology, Department of Medicine, University of Virginia, Charlottesville, Virginia, 22908, USA
}

(Correspondence should be addressed to Anargyros N Moulas; Email: moulas@teilar.gr)

\begin{abstract}
Objective: To determine the effect of repeated treatments with the growth hormone secretagogue (GHS) L-163,255 on the pulsatile release of GH when administered in meal-fed rats before and after feeding.

Design: The first group of rats (AL, $n=6$ ) had food available ad libitum. The second (restricted, R, $n=6$ ), third (GHSB, $n=6$ ), and fourth (GHSA, $n=6$ ) groups were fed from 1100 to $1400 \mathrm{~h}$. Groups GHSB and GHSA were given GHS by gavage, $3.0 \mathrm{mg} / \mathrm{kg} \mathrm{L}-163,255$, at $1000 \mathrm{~h}$ (before feeding, B) and at $1500 \mathrm{~h}$ (after feeding, A) respectively. Three weeks after the initiation of the treatment, blood samples were collected at 10-min intervals over $6 \mathrm{~h}$, and $\mathrm{GH}$ levels were determined.

Results: In group R, the concentrations of GH were higher before feeding $(17.6 \pm 2.4 \mathrm{ng} / \mathrm{ml})$ than during feeding $(11.2 \pm 1.2 \mathrm{ng} / \mathrm{ml}), P<0.05$. The average concentrations of the peak in response to GHS were higher when GHS was administered before $(121.70 \pm 33.68 \mathrm{ng} / \mathrm{ml})$ than after $(49.67 \pm$ $17.87 \mathrm{ng} / \mathrm{ml}$ ) feeding. The mass of $\mathrm{GH}$, as calculated by deconvolution analysis was also higher in the GHSB group than in the GHSA group $(251.6 \pm 64.1 \mathrm{ng} / \mathrm{ml}$ per $\min$ vs $85.3 \pm 22.9 \mathrm{ng} / \mathrm{ml}$ per $\min$ respectively, $P<0.05)$.

Conclusion: L-163,255 is effective in inducing GH release after repeated oral administration in rats. The effectiveness is greater when GHS is administered before rather than after feeding in meal-fed animals.
\end{abstract}

European Journal of Endocrinology 147 143-148

\section{Introduction}

Growth hormone (GH) is a peptide hormone, produced and secreted from somatotrophs in the anterior pituitary gland. It exerts its action by binding to $\mathrm{GH}$ receptor in target tissues. GH is released in episodic bursts in a pulsatile manner, regulated by episodic changes in the concentration of two other hormones, growth hormone releasing hormone (GHRH) and somatostatin (SS). GHRH stimulates secretion whereas SS inhibits GH secretion (1). Growth hormone secretion can also be induced by synthetic ligands. Several such GH releasing substances, different from the naturally occurring GHRH, have been synthesized. These substances are called growth hormone secretagogues (GHS). The GHS are synthetic peptidyl and non-peptidyl molecules that exhibit strong GH releasing activity in vivo and in vitro. GHS induces GH secretion in a dose-dependent manner when administered i.v. or orally $(2-5)$.
The GH secretagogues act through the growth hormone secretagogue receptor (GHS-R), a G protein coupled receptor (6). Ghrelin, an acylated stomach peptide, was recently reported as the first known endogenous ligand for this receptor (7). More endogenous ligands have been reported subsequently ( 8 , 9). The GHS receptor cannot be activated by GHRH or somatostatin and the $\mathrm{GH}$ secretagogues affect $\mathrm{GH}$ secretion via a mechanism that is different from that of GHRH. Interestingly, the secretagogues and the peptidergic GH releasing hormone are synergistic with respect to $\mathrm{GH}$ release $(4-6,9)$.

The oral bioavailability of the first known peptidyl GHS was limited. Recently available GH secretagogues now include small-molecule, non-peptide secretagogues that can be administered orally to stimulate significant GH secretion (2).

The particular secretagogue used in this study is the spiropiperidine, L-163,255, developed by Merck and Co. Inc. It has been found to be very effective at stimulating 
the secretion of GH, and subsequent elevation of circulating levels of insulin-like growth factor-I (10).

It is well known that $\mathrm{GH}$ is secreted in a pulsatile manner in episodic bursts (1). Studies in steers have shown a specific pattern of GH secretion that is related to feeding (11-13). Animals were 'meal-fed', such that they received food for only a certain period of time. In this case, the animals were fed from 0730-0930 h (12) or from 1000 to $1200 \mathrm{~h} \mathrm{(13).} \mathrm{Under} \mathrm{these}$ conditions, $\mathrm{GH}$ was secreted in relatively high levels $1-3 \mathrm{~h}$ before the feeding period. During the feeding period GH was secreted at a very low level. After feeding, GH levels were relatively low, but started to rise again. Intravenous injection of bovine GHRH induced a rise in $\mathrm{GH}$ concentration in meal-fed steers. This rise was significantly higher when GHRH was injected 20 min before feeding than when it was injected 20 min after feeding (13).

There are no data available concerning the effect of GHS L-163,255 on the pulsatile release of GH, when administered to meal-fed rats. The present study was designed to determine the possible effects of GHS L-163,255 on the pulsatile release of GH when administered orally in meal-fed rats before and after feeding.

Repeated treatment with growth hormone secretagogues results, in some cases, in a desensitisation and a reduced $\mathrm{GH}$ release in response to these substances (2). A second objective of this study was to test whether the effect of GHS L-163,255 on GH release in rats is sustained after repeated oral treatment.

\section{Materials and methods}

All animal procedures were approved by the Institutional Animal Care and Use Committee (IACUC) of Virginia Commonwealth University (VCU).

Male Sprague-Dawley rats (Charles River Laboratories, Wilmington, MA, USA) were obtained at 125$150 \mathrm{~g}$ body weight (approximately 38-42 days of age). The animals were kept in individual steel cages in animal quarters controlled for temperature (21$23^{\circ} \mathrm{C}$ ) and light (14 h light:10 h darkness).

All rats had free access to water. Animals were fed a high protein diet consisting of $35.3 \%$ casein (Harlan Teklad, Madison, WI, USA), 34.7\% sucrose, 15\% cornstarch, 5.0\% fibre-celufill (Harlan Teklad), 5.0\% corn oil, 3.5\% mineral mix (AIN93, Harlan Teklad), 1.0\% vitamin mix (AIN93, Harlan Teklad), 0.3\% DL-methionine (Sigma Chemical Co., St Louis, MO, USA) and $0.2 \%$ choline bitartrate (Sigma Chemical Co.).

The animals were divided into four weight-matched groups. The first group (AL, $n=6$ ) was fed the high protein diet which was available ad libitum (AL). The second group (R, $n=6$ ) was 'meal-fed' such that the availability of the high protein diet was restricted to a period from 1100 to $1400 \mathrm{~h}$. The third group (GHSB, $n=6$ ) was food restricted with L-163,255 given one hour before (B) feeding (i.e. at $1000 \mathrm{~h}$ ). The GHS was given by gavage at a dose of $3.0 \mathrm{mg} / \mathrm{kg}$ body weight. The frequency of administration was twice a week. Due to the limitations in the numbers of animals that could be sampled on one day (3), the animals received L-163,255 either on Monday and Friday or on Tuesday and Saturday. The fourth group (GHSA, $n=6$ ) was food restricted and L-163,255 was given $1 \mathrm{~h}$ after (A) the end of the feeding period (i.e. at $1500 \mathrm{~h}$ ). Route, dose and intervals of administration were the same as for the GHSB group. The two control groups (AL and $\mathrm{R}$ ) were gavaged with saline at the same time intervals as the GHSB animals.

Body weight and food consumption were measured daily. Calculation of food intake was made by dividing the amount of food consumed per $100 \mathrm{~g}$ body weight ( $\mathrm{g}$ food/100 g body weight). Calculation of food efficiency was made by dividing the amount of weight gained by the amount of food consumed ( $g$ weight gained/g food consumed).

For the blood sampling, polyvinyl catheters (Dural Plastics Ltd, Auburn, Australia) containing $50 \mathrm{IU} / \mathrm{ml}$ heparin, were implanted into the right atrium of all rats through the right external jugular vein. After testing, the catheters were plugged with a stainless steel plug. The operation was performed under ether anaesthesia. After recovering on a heating pad the rats were allowed to return to their cages. This operation was performed three days before sampling in order to allow the rats to adapt to the catheters.

Blood sampling began three weeks after the initiation of the GHS treatment for the determination of $\mathrm{GH}$ in plasma. Thirty minutes before sampling, a 50-cm polyvinyl extension was attached to the catheter with the use of a small piece of stainless steel tubing. Blood samples were collected at 10-min intervals for a period of $6 \mathrm{~h}$. Sampling started $30 \mathrm{~min}$ before oral administration of saline or GHS by gavage. For groups $\mathrm{AL}, \mathrm{R}$ and GHSB sampling lasted from $0930 \mathrm{~h}$ to $1530 \mathrm{~h}$ and for group GHSA it lasted from $1430 \mathrm{~h}$ to $2030 \mathrm{~h}$.

Blood samples $(0.25 \mathrm{ml})$ were collected with heparinized $1.0 \mathrm{ml}$ syringes via the polyvinyl catheters and transferred into $1 \mathrm{ml}$ heparinized conical tubes. Plasma was immediately separated with centrifugation and stored at $-20^{\circ} \mathrm{C}$ until assayed for $\mathrm{GH}$ by RIA. The red blood cells were re-suspended up to the initial volume in $0.9 \% \mathrm{w} / \mathrm{v}$ sodium chloride solution, and re-injected into the animal via the catheter, after the subsequent sample.

Assay for $\mathrm{GH}$ was performed with a radioimmunoassay (RIA) kit containing rat GH RP-2 as reference preparation, provided by Dr A F Parlow and the National Hormone and Pituitary Program of the NIDDK. The intra-assay coefficient of variation was $6.6 \%$ at $1.0 \mathrm{ng} /$ tube and the interassay coefficient of variation was $10.5 \%$ at $0.625 \mathrm{ng} /$ tube. Assay sensitivity was $4.0 \mathrm{ng} / \mathrm{ml}$. 
The pulsatility of the GH secretion was calculated with the multiple parameter deconvolution method of Veldhuis et al. (14) and Veldhuis and Johnson (15). This method uses the plasma concentrations of $\mathrm{GH}$ for the calculation of the mean GH secretory burst area (mass) for the specific $\mathrm{GH}$ burst that followed GHS treatment. It also allowed for the calculation of other parameters of $\mathrm{GH}$ pulsatile secretion over the 6-h period. These other parameters included: basal secretion, half-duration, half-life, number of bursts, interburst interval, burst amplitude, pulsatile production rate, and total production rate.

Intergroup comparisons were carried out with analysis of variance (ANOVA) followed by Duncan's Multiple Range test in case of significance. All results are presented as means \pm S.E.M.

\section{Results}

In general, the dose of L-163,255 used in these experiments caused no significant changes in food intake, weight gain, or food efficiency.

Figure 1 illustrates the mean plasma GH concentrations during the 6-h sampling period. In the AL group, the normal pattern for the GH secretion was observed. In the food-restricted group, R, the concentrations of $\mathrm{GH}$ were significantly higher before feeding $(17.6 \pm 2.4 \mathrm{ng} / \mathrm{ml}$ from $0930 \mathrm{~h}$ to $1100 \mathrm{~h})$ than during feeding $(11.2 \pm 1.2 \mathrm{ng} / \mathrm{ml}$ from $1110 \mathrm{~h}$ to $1400 \mathrm{~h}, \mathrm{P}<0.05)$. After the feeding period, the GH levels were $11.0 \pm 2.9 \mathrm{ng} / \mathrm{ml}$ from 1410 to $1530 \mathrm{~h}$.

A marked increase in circulating $\mathrm{GH}$ levels was observed in groups GHSA and GHSB with a maximum at 30 min after the administration of the GHS L-163,255. All six rats of the GHSB group responded to the GHS with a GH peak after 30-40 min (peak height range $38-248 \mathrm{ng} / \mathrm{ml}$ ). Five out of six rats of the GHSA group responded to the GHS with a GH peak (peak height range $46-105 \mathrm{ng} / \mathrm{ml}$ ).

The mean values for GH 30 min after saline or GHS administration by gavage were $14.32 \pm 4.10 \mathrm{ng} / \mathrm{ml}$, $23.09 \pm 8.31 \mathrm{ng} / \mathrm{ml}, \quad 121.70 \pm 33.68 \mathrm{ng} / \mathrm{ml}$ and $49.67 \pm 17.87 \mathrm{ng} / \mathrm{ml}$ in groups AL, R, GHSB and GHSA respectively. The GH concentration at that time was significantly higher in the GHSB group than in the saline-treated groups (AL vs GHSB $P<0.05$, R vs GHSB $P<0.05)$. In the GHSA group, a peak in response to GHS was also observed. However, the difference between groups GHSA and R was not significant despite the clear GH peak in the GHSA group (R vs GHSA $P=0.2$ ). Comparison of the peaks of $\mathrm{GH}$ $30 \mathrm{~min}$ after GHS administration showed that the administration of GHS before feeding stimulated a higher peak of GH than when GHS was given after feeding $(P<0.05)$.

Figure 2 shows the results of deconvolution analyses of the individual burst mass immediately after GHS administration. The mass of GH secreted by the pituitary gland in response to GHS before feeding (GHSB) was significantly greater than that stimulated by GHS after feeding (GHSA) $(251.6 \pm 64.1 \mathrm{ng} / \mathrm{ml}$ per min vs $85.3 \pm 22.9 \mathrm{ng} / \mathrm{ml}$ permin respectively, $P<0.05)$. In contrast to these significant differences, there was no significant difference in any of the overall parameters of GH pulsatility during the 6-h period of sampling.

Table 1 shows the average values for weight gain, food intake and food efficiency (means \pm s.E.M.) in the

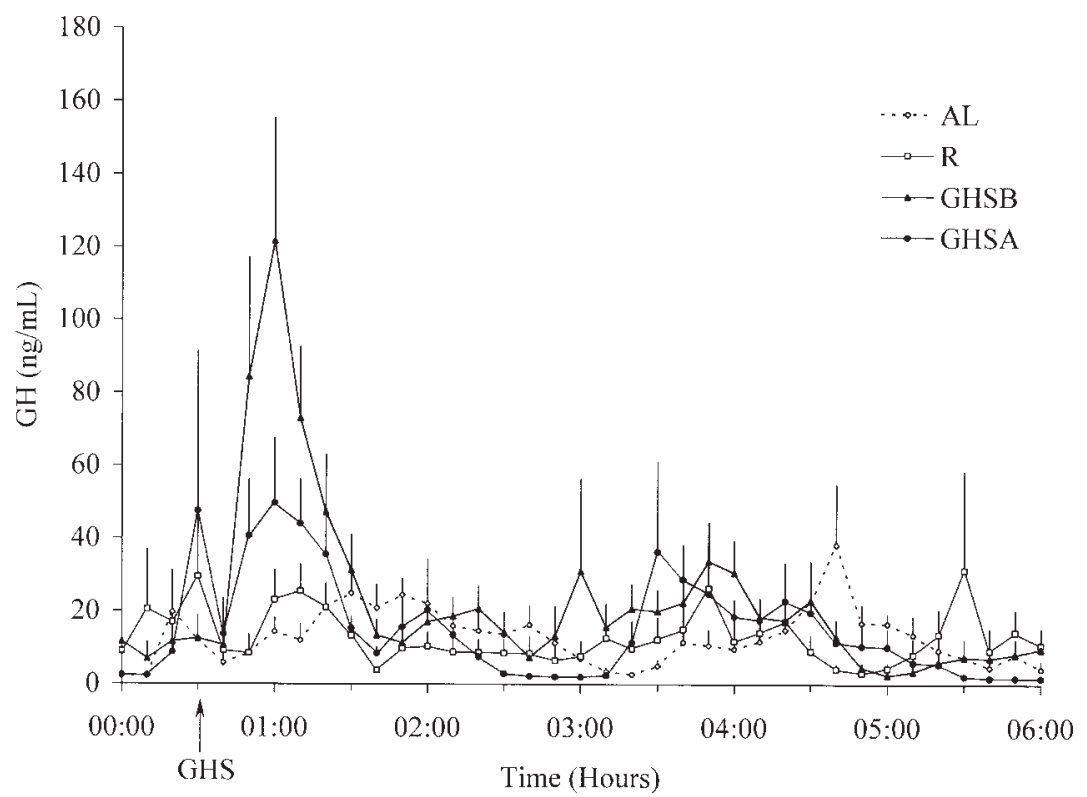

Figure 1 Plasma GH responses to oral administration of GHS L-163,255 $(3.0 \mathrm{mg} / \mathrm{kg}$ body weight) or saline in rats before and after feeding. Sampling was carried out every 10 min over a 6 -h period. Group AL had food available ad libitum and groups R, GHSB and GHSA were fed only from $1100 \mathrm{~h}$ to $1400 \mathrm{~h}$. Group R was given saline. Group GHSB was given L-163,255 60 min before the feeding period and group GHSA was given L-163,255 $60 \mathrm{~min}$ after feeding. Each value represents the mean \pm S.E.M. of six animals. The arrow indicates the time that saline or GHS was administered. 


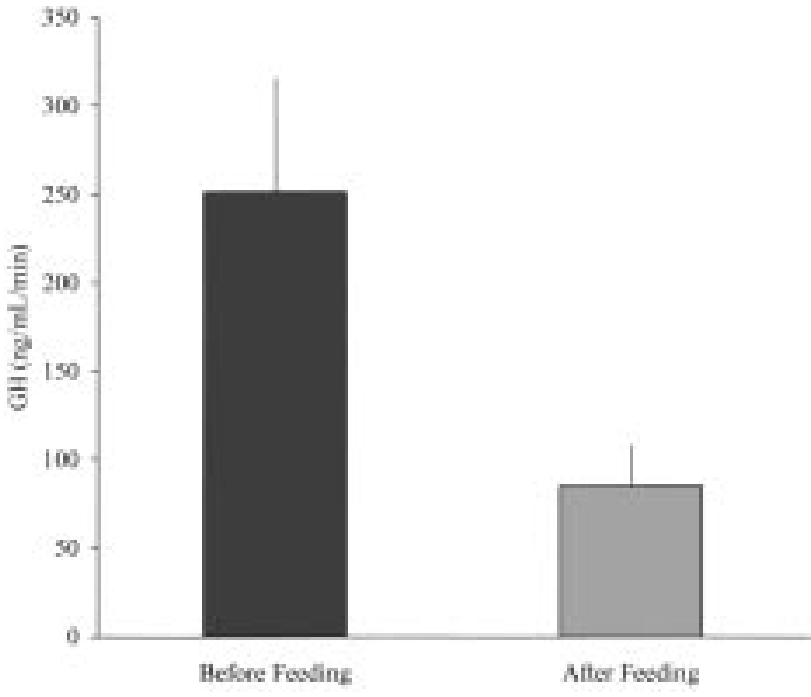

Figure 2 Mass of GH secretory bursts after oral administration of GHS L-163,255 (3.0 mg/kg body weight) as determined by deconvolution analyses. In the GHSB group, L-163,255 was administered 60 min before feeding (Before Feeding) and in the GHSA group, L-163,255 was administered 60 min after a 3-h restricted feeding period (After Feeding). $P<0.05$, GHSB vs GHSA.

four groups of rats. Group AL had higher weight gain and food intake. No significant differences were observed between groups R, GHSB and GHSA.

\section{Discussion}

Growth hormone is released by the pituitary gland in episodic pulses in the rat, human, and other mammals (1). Feeding is known to affect GH secretion (11-13). The GH pulses are known to increase before feeding, and to decrease during feeding and for up to $2-3 \mathrm{~h}$ afterwards $(11-13)$. Consistent with these results, the rats of the restricted $(\mathrm{R})$ group in our experiment had lower average $\mathrm{GH}$ concentrations during the feeding period from $11.10 \mathrm{~h}$ to $1400 \mathrm{~h}$ than during the period before feeding.

The GHS L-163,255 has been found to be effective in stimulating GH secretion in pigs $(10,16)$, horses (17) and chickens (18). This is the first observation about the effect of this GHS in rats. In the GHS-treated animals a clear peak in response to GHS was observed $30 \mathrm{~min}$ after gavage.
In a previous study, reduction of the serum GH response to an injection of growth hormone releasing factor (GRF) was observed when steers, fed once a day at $1400 \mathrm{~h}$, were injected with GRF after feeding. The best response to GRF was observed when the GRF was injected $2 \mathrm{~h}$ before feeding (12). In another experiment, injection of bovine GHRH to meal-fed steers before feeding caused a significantly higher increase in circulating GH than after feeding (13).

The possible effect of restricted feeding on the response to GHS is not known. Our data show that there is a significantly higher impact on circulating $\mathrm{GH}$ when the GHS is administered before feeding. The administration of GHS caused a significantly higher release of $\mathrm{GH}$ when it was given before feeding than after feeding. The mass of $\mathrm{GH}$ that was secreted after the GHS stimulus, as calculated with deconvolution analysis, was significantly higher in GHSB than in GHSA $\quad(251.6 \pm 64.1 \mathrm{ng} / \mathrm{ml}$ vs $85.3 \pm 22.9 \mathrm{ng} / \mathrm{ml}$, $P<0.05)$ rats. Likewise, the average peak height 30 min after GHS was also higher in the GHSB than in the GHSA group.

With respect to the mechanism by which GHS, or other GH-releasing stimuli, might be more effective before, in contrast to after, a restricted period of feeding, we would hypothesize an important role for the level of somatostatin tone from the hypothalamus. McMahon et al. (13) reported a relatively low level of activity of somatostatin neurons during the period before restricted feeding in steers. We would suspect that a low level of somatostatin coming from the hypothalamus would allow for a greater response to GH-releasing stimuli. On the other hand, a relatively high level of somatostatin tone after feeding might be important to a lower level of GH stimulation.

Christensen et al. (17) administered the GHS L-163,255, i.v., to mares at doses of 1.0 and $5.0 \mathrm{mg} / \mathrm{kg}$ body weight. Those animals were fed twice daily, at $0800 \mathrm{~h}$ and at $1500 \mathrm{~h}$ and the GHS was injected at $1300 \mathrm{~h}$. A GH peak in response to GHS was observed $34 \mathrm{~min}$ after injection. There was no difference in $\mathrm{GH}$ release between the 1.0 and the $5.0 \mathrm{mg} / \mathrm{kg}$ dose. In our experiment, the GH release in response to oral administration of L-163,255 in a dose of $3.0 \mathrm{mg} / \mathrm{kg}$ body weight was observed after a time period of $30 \mathrm{~min}$. This suggests that the GHS L-163,255 is quickly absorbed through the intestinal system and acts quickly. Thus, oral administration is

Table 1 Weight gain, food intake and food efficiency in the four groups of rats studied. Results are means \pm S.E.M.

\begin{tabular}{lcccc}
\hline Group & $\boldsymbol{n}$ & $\begin{array}{c}\text { Weight gain } \\
\text { (g/day) }\end{array}$ & $\begin{array}{c}\text { Food intake } \\
\text { (g/100 g body weight) }\end{array}$ & $\begin{array}{c}\text { Food efficiency } \\
\text { (g of food intake/g weight gained) }\end{array}$ \\
\hline AL & 6 & $8.38 \pm 2.57$ & $9.94 \pm 0.53$ & $0.55 \pm 0.19$ \\
R & 6 & $5.39 \pm 2.82$ & $7.65 \pm 1.05$ & $0.46 \pm 0.21$ \\
GHSB & 6 & $4.83 \pm 2.70$ & $7.45 \pm 1.00$ & $0.45 \pm 0.22$ \\
GHSA & 6 & $4.99 \pm 2.80$ & $7.42 \pm 1.02$ & $0.45 \pm 0.19$ \\
\hline
\end{tabular}


effective which can obviate the necessity for intravenous injection.

This is the first observation, to our knowledge, about the effect of GHS L-163,255 in rats. Our results confirm the observation in other species of animals that the GHS L-163,255 can cause significant growth hormone release $(10,16-18)$. In the rat there is a maximum release about $30 \mathrm{~min}$ after the oral administration of GHS.

A desensitization and sustained amplification of pulsatile profile of $\mathrm{GH}$ release has been observed after repeated treatment with GH secretagogues (2). Repeated administration of the MK-0677 GHS to dogs resulted in a decrease in the GH response by $41-77 \%$ (19). In our experiment, the GH release in response to the GHS was observed after a 3-week treatment with GHS in bi-weekly intervals. Although the design of our experiment did not allow the measurement of the response to L-163,255 after first time administration for comparison, our data suggest that this secretagogue is capable of effectively stimulating GH secretion even after repeated administration.

In contrast to the significant acute stimulation of $\mathrm{GH}$ release within about $30 \mathrm{~min}$ after treatment, GHS did not exert a significant effect on the overall parameters of $\mathrm{GH}$ pulsatility during the total sampling period of $6 \mathrm{~h}$. These results lead to the probability that GHS can acutely affect $\mathrm{GH}$ secretion without necessarily disrupting its overall, long-term, pulsatile pattern.

Growth hormone secretion is known to be significantly related to 'fasted' and 'fed' states. In humans, GH is secreted at significantly higher levels during the fasted state (20). We had not initially considered this study to be related to 'fasted' versus 'fed' states. However, one could consider the time immediately preceding a 3-h/day feeding period to be a relatively 'fasted' state. Likewise, the period after feeding would be a 'fed' state. Despite the typical incongruence of GH pulsatile secretion in rats to that of humans with respect to fasting, i.e. rats typically show decreased GH secretion during fasting (21), the current data indicate that rats are very likely to be more responsive to GH-releasing stimuli during a period in which they have certainly been without food for a relatively long period of time. It is possible that, although the pituitary gland may be more responsive to GH-releasing stimuli, those stimuli do not come down from the hypothalamus at that time.

We have actually thought of the current studies as being designed around the 'anticipation of feeding'. In that sense they have not necessarily been studies of the 'fasted' state per se. Studies of potential differences between 'fasting' and 'anticipation of feeding' might be useful for a better understanding of GH physiology and growth.

Despite the clear acute effect on GH release, no significant difference in growth was observed in the GHSB and GHSA groups compared with the restricted group. This may be due to the meal feeding itself, or to the dose of GHS which was not sufficient, or to some feedback effect. Tests with higher doses of GHS should be conducted.

We conclude that L-163,255 is effective in inducing $\mathrm{GH}$ release after repeated oral administration at a dose of $3 \mathrm{mg} / \mathrm{kg}$ in rats. The effectiveness of this GHS is greater when it is administered before feeding than after feeding in meal-fed animals. This observation may be useful for the optimization of the effectiveness of this secretagogue.

\section{Acknowledgements}

The authors would like to express their gratitude Ms Kenley Ward for her help with the animals and the sampling procedures, and to Ms Paula Azimi for her execution of the deconvolution analyses. We would also like to thank Dr A F Parlow and the National Pituitary Hormone Distribution Program of NIDDK for the rat GH radioimmunoassay kit. These studies were supported by a Jeffress Foundation Grant \#J-544 (R J K), and NIH Grants AG 14799 (J D V), and DK 50419 and DK 07761 (J C M C).

\section{References}

1 Giustina A \& Veldhuis JD. Pathophysiology of the neuroregulation of growth hormone secretion in experimental animals and the human. Endocrine Reviews 199819 717-797.

2 Smith RG, Van der Ploeg LH, Howard AD, Feighner SD, Cheng K, Hickey GJ, Wyvratt MJ Jr et al. Peptidomimetic regulation of growth hormone secretion. Endocrine Reviews $1997 \mathbf{1 8}$ 621-645.

3 Smith RG, Palyha OC, Feighner SD, Tan CP, McKee KK, Hreniuk DL et al. Growth hormone releasing substances: types and their receptors. Hormone Research 199951 1-8.

4 Robinson IC. Control of growth hormone $(\mathrm{GH})$ release by $\mathrm{GH}$ secretagogues. Novartis Foundation Symposium $2000 \quad \mathbf{2 2 7}$ 206-224.

5 Ghigo E, Arvat E, Broglio F, Giordano R, Gianotti L, Muccioli G et al. Endocrine and non-endocrine activities of growth hormone secretagogues in humans. Hormone Research 199951 9-15.

6 Howard AD, Feighner SD, Cully DF, Arena JP, Liberator PA, Rosenblum CI et al. A receptor in pituitary and hypothalamus that functions in growth hormone release. Science $1996 \mathbf{2 7 3}$ 974-977.

7 Kojima M, Hosoda H, Date Y, Nakazato M, Matsuo H \& Kangawa $\mathrm{K}$. Ghrelin is a growth-hormone-releasing acylated peptide from stomach. Nature $1999 \mathbf{4 0 2}$ 656-660.

8 Hosoda H, Kojima M, Matsuo H \& Kangawa K. Purification and characterization of rat des-Gln14-Ghrelin, a second endogenous ligand for the growth hormone secretagogue receptor. Journal of Biological Chemistry 2000275 21995-22000.

9 Smith RG, Leonard R, Bailey AR, Palyha O, Feighner S, Tan C et al. Growth hormone secretagogue receptor family members and ligands. Endocrine 200114 9-14.

10 Chang CH, Rickes EL, McGuire L, Frazier E, Chen H, Barakat K et al. Growth hormone $(\mathrm{GH})$ and insulin-like growth factor I responses after treatments with an orally active $\mathrm{GH}$ secretagogue L-163,255 in swine. Endocrinology $19961374851-4856$.

11 Wheaton JE, Ar-Raheem SN, Massari YG \& Marcek JM. Twentyfour-hour growth hormone profiles in Angus steers. Journal of Animal Science $1986 \mathbf{6 2} 1267-1272$. 
12 Moseley WM, Alaniz GR, Claflin WH \& Krabill LF. Food intake alters the serum growth hormone response to bovine growth hormone-releasing factor in meal-fed Holstein steers. Journal of Endocrinology $1988117253-259$.

13 McMahon CD, Chapin LT, Lookingland KJ, Radcliff RP \& Tucker HA. Feeding reduces activity of growth hormone-releasing hormone and somatostatin neurons. Proceedings of the Society for Experimental Biology and Medicine 2000223 210-217.

14 Veldhuis JD, Carlson ML \& Johnson ML. The pituitary gland secretes in bursts: appraising the nature of glandular secretory impulses by simultaneous multiple parameter deconvolution of plasma hormone concentrations. PNAS $1987 \mathbf{8 4}$ 7686-7690.

15 Veldhuis JD \& Johnson ML. Deconvolution analysis of hormone data. Methods in Enzymology 1992210 539-575.

16 Drisko JE, Faidley TD, Zhang D, McDonald TJ, Nicolich S, Hora DF et al. Administration of a nonpeptidyl growth hormone secretagogue, L-163,255, changes somatostatin pattern, but has no effect on patterns of growth hormone-releasing factor in the hypophyseal-portal circulation of the conscious pig. Proceedings of the Society for Experimental Biology and Medicine 1999222 $70-77$.

17 Christensen RA, Malinowski K, Scanes CG \& Hafs HD. Pulsatile release of somatotropin related to meal feeding and somatotropin response to secretagogues in horses. Journal of Animal Science $1997752770-2777$.

18 Geris KL, Hickey GJ, Vanderghote A, Kuhn ER \& Darras VM. Synthetic growth hormone secretagogues control growth hormone secretion in the chicken at pituitary and hypothalamic levels. Endocrine 200114 67-72.

19 Hickey GJ, Jacks TM, Schleim KD, Frazier E, Chen HY, Krupa D et al. Repeat administration of the GH secretagogue MK-0677 increases and maintains elevated IGF-I levels in beagles. Journal of Endocrinology $1997 \mathbf{1 5 2} 183-192$.

20 Hartman ML, Pezzoli SS, Hellmann PJ, Suratt PM \& Thorner MO. Pulsatile growth hormone secretion in older persons is enhanced by fasting without relationship to sleep stages. Journal of Clinical Endocrinology and Metabolism 199681 2694-2701.

21 Bruno JF, Olchovsky D, White JD, Leidy JW, Song J \& Berelowitz M. Influence of food deprivation in the rat on hypothalamic expression of growth hormone-releasing factor and somatostatin. Endocrinology $19901272111-2116$.

Received 7 November 2001

Accepted 20 March 2002 